\title{
The Trade Creating Effects of Business and Social Networks: Evidence from France *
}

\author{
Pierre-Philippe Combes ${ }^{\dagger} \quad$ Miren Lafourcade Thierry Mayer $^{\ddagger}$
}

August 9, 2004

\begin{abstract}
Using theory-grounded estimations of trade flow equations, this paper investigates the role that business and social networks play in shaping trade between French regions. The bilateral intensity of networks is quantified using the financial structure and location of French firms and bilateral stocks of migrants. Compared to a situation without networks, migrants are shown to double bilateral trade flows, while networks of firms multiply trade flows by as much as four in some specifications. Finally, taking network effects into account divides the estimation of the impact of transport costs and of the effect of administrative borders by around three.
\end{abstract}

JEL classification: F12, F15

Keywords: migrants, business groups, networks, border effects, gravity, structural estimation.

\footnotetext{
${ }^{*}$ This paper is produced as part of a CEPR Research Network on The Economic Geography of Europe: Measurement, Testing and Policy Simulations, funded by the European Commission under the Research Training Network Programme (Contract No: HPRN-CT-2000-00069). We thank Jean-Eric Thomas for having kindly made the trade flow data available to us. We are also grateful to Johannes Bröcker, Harry Flam, Laurent Gobillon, Keith Head, Christiane Krieger-Boden, and to seminar participants (ERWIT 2002, HWWA Workshop on border regions 2002, and the Econometric Society North American 2004 Winter Meetings) for fruitful comments and discussions. Comments by a co-editor and two anonymous referees were crucial in the improvement of the paper. We gratefully acknowledge the hospitality of the French Ministry of Transport Economics Department (SES-DAEI) and of Boston University, as well as the financial support from SES-DAEI and from NATO (Combes' advanced fellowship grant).

${ }^{\dagger}$ CERAS-ENPC, 48 Bd Jourdan, 75014 Paris, France. CNRS researcher also affiliated with the CEPR (combes@enpc.fr, http://www.enpc.fr /ceras/combes/).

${ }^{\ddagger}$ Université d’Evry Val d’Essonne (IUT - GLT Department) and CERAS-ENPC, 48 Bd Jourdan, 75014 Paris, France (lafourca@enpc.fr, http://www.enpc.fr/ceras/lafourcade/).

${ }^{\S}$ Corresponding author: CERAS-ENPC, 48 Bd Jourdan, 75014 Paris, France. Also affiliated with TEAM (Université de Paris I), CEPII and the CEPR (tmayer@univ-paris1.fr, http://team.univ-paris1.fr/teamperso/mayer/thierry.htm).
} 


\section{Introduction}

It is one of the most widely accepted results in international economics that trade is impeded by distance, as testified by the large set of papers estimating standard gravity equations. A more recent finding, initiated by McCallum (1995), is that, in addition to the impact of distance, the crossing of national borders also sharply reduces trade 1 Furthermore, contiguity has also been largely shown to have a positive impact on trade volumes. Hence, spatial proximity matters for trade, but in a quite complex way that goes beyond the simple (log linear) impact of geographical distance. More work is still needed to understand fully the reasons why these various notions of proximity matter so much for trade. Obstfeld and Rogoff (2000) for instance refer to the border effect as one of the "six major puzzles in international macroeconomics". Although going a long way towards enlightening this puzzle through a much improved link with theory, Anderson and van Wincoop (2003) are left with non trivial "unexplained" trade impediments. In parallel, a recent strand of the literature surveyed by Rauch (2001) and Wagner et al. (2002) suggests that business and social networks operating across borders might promote trade notably through a reduction in information costs. We try here to provide evidence linking the two phenomena. This paper empirically assesses the trade-creating effects of business and social networks and quantifies the share of trade impediments (distance, borders, contiguity) that can be explained by those networks.

Networks can promote trade through different channels. The literature has proposed two main economic mechanisms: The reduction of information costs and the diffusion of preferences. The first channel relies on the potential alleviation of costs incurred by economic agents when gathering information about distant markets. Indeed, informational barriers make it difficult both for consumers to obtain relevant information on the goods produced in another location and for non-local producers to learn the tastes of consumers or to be aware of the practices of local retailers. Both effects increase transaction costs and thus perceived prices, which has a negative impact on trade flows. The empirical work has used observed distributions of international migrants to identify this effect. It is indeed likely that hosting a large number of migrants from other areas tend to promote trade because they keep active linkages with their networks at "home": "Immigrants know the characteristics of many domestic buyers and sellers and carry this knowledge abroad" (Rauch, 2001, p.1184). Next to migrant effects, it has been suggested that networks of firms can also contribute to alleviate information problems in the international marketplace, notably through foreign direct investment 2 The fall of information costs inside networks also has an indirect positive effect on trade working through better enforcement of contracts. Gould (1994) and Rauch (2001) detail how the reciprocal knowledge of trade partners can help to reduce costly opportunism in business, networks being substitutes of contract enforcement laws. Reputation effects are likely to be magnified inside a network, due to the increased reciprocal knowledge and number of interactions across members and the consequent higher speed of information flows. Rauch and Trindade (2002) also mention the possible common enforcement of sanctions by the entire network against the deviating member as a means to deter violations of contracts and commitments.

The second channel for the impact of networks on trade is their role as a conduit for the diffusion of preferences. Consumers may have a home bias that translates in a higher valuation for the goods produced locally, either because of persistence in consumption habits inherited from a period where markets were more fragmented or simply because of "chauvinism". The presence of foreigners may

\footnotetext{
${ }^{1}$ Wei (1996), Helliwell (1996) and (1997), Nitsch (2000), Head and Mayer (2000), Anderson and van Wincoop (2003) and Chen (2003) are all examples of recent papers stating that the impact of national borders on trade volumes is all but negligible among seemingly highly integrated countries.

${ }^{2}$ Rauch (2001) notably claims that "foreign direct investment by one or more members of a domestic business group has the same effect [as the migrant effects]" (p.1185). More generally, strategic behavior inside networks of financiallylinked enterprises might also affect trade patterns through subtle effects involving coordination and possible building of barriers to entry.
} 
alter this tendency. Indeed a high number of migrants might raise imports from origin countries both because migrants keep part of their taste for home goods and because nationals partly acquire a taste for those new varieties. Although it is possible to draw some inferences about the relative strengths of those two channels, identifying them separately in a rigorous way is an important but difficult task $3^{3}$

Gould (1994), Head and Ries (2001), Girma and Yu (2002), Rauch and Trindade (2002) and Wagner et al. (2002) illustrate the trade-creating effect of networks using estimates of migration variables in gravity-type equations. The first three papers estimate the impact of migrants settled in the United States, Canada and the United Kingdom respectively on national trade flows, while Wagner et al. (2002) use information on the trade volumes of each Canadian provinces with a set of foreign countries, coupled with the provincial stocks of migrants from each of those trade partners. All papers find positive impacts of migrations on trade volumes (see Wagner et al., 2002, for a detailed comparative analysis of the papers). An interesting result is that the effect of migrants is not shown to be consistently higher for imports than for exports. As just highlighted, this casts doubt on the empirical importance of the preference channel, and therefore supports the information channel. Rauch and Trindade (2002) strengthen this support in their study of the impact of ethnic Chinese residents in origin and destination countries on the amount traded by those countries. Their analysis mostly abstract from the preference channel because the observations involving China as a trade partner are only a marginal part of the sample 4 One of their key results is that networks between Chinese residents, when at the levels reached in South-East Asian countries, increase trade by $60 \%$. Additional evidence of the role of the information channel is provided through a distinction of the impact of networks across different types of goods, ranging from most homogenous to most differentiated. The expectation is that for high levels of differentiation, the need and efficiency of networks as information conduits should be magnified. While networks appear to matter for all types of goods, the effects steadily increase with the differentiation of products indeed, which confirms the intuition. Put together, the existing work on migration and trade points towards a higher relevance of the information-related channels, a result we also find some evidence of in this paper.

The empirical evidence related to the effects of networks of firms on trade is much scarcer than the one on the trade impact of migration patterns. Most of the evidence relies on the particular case of the links between member firms of Japanese keiretsus. Belderbos and Sleuwaegen (1998) show that the share of production exported to the European Union by a Japanese electronic firm is substantially higher if this firm is a component subcontractor in a vertical keiretsu and if the parent firm has previously invested in the EU. A related empirical literature has shown that Japanese imports are significantly lower in industries where a large share of sales is made by keiretsu members (Lawrence, 1993, surveys early papers in this vein, while Head et al., 2004, is a recent application to the specific case of car parts). This last finding suggests that membership of a keiretsu network facilitates trade between member firms at the expense of outsiders, although it is unclear whether this effect comes from increased efficiency or exclusionary behavior. The most important innovation of our paper consists in providing new and more systematic results on the impact of networks of firms on trade and in comparing it to the strength of migrant ones.

More precisely, we estimate the trade-creating effects of business and social networks on interregional trade flows between 94 French regions. The impact of social networks is quantified using

\footnotetext{
${ }^{3}$ Presumably, the preference effect takes place for networks created and maintained by individuals at the destination of the trade flow only (i.e. the impact of immigrants on imports). By contrast, migrant networks at the origin of the trade flow (i.e. the impact of immigrants on exports) and firm networks should encompass information effects only. Some papers in the literature compare the effect of migrants on imports and exports so as to assess whether the information channel is larger than the preferences one. Estimating the impact of networks of firms, as done in this paper, makes it possible to go one step further (although not all the way) in this direction. If the empirics reveal that networks of firms have a stronger effect than networks of migrants, it can be interpreted as evidence of stronger informational effects within networks of firms, combined with a level of preference effects sufficiently low to be overcome by the difference in information effects.

${ }^{4}$ The authors even control fully for this effect in a robustness check set of regressions that excludes Chinese trade.
} 
bilateral migrant stocks. Business network effects are assessed by using data on the links between plants belonging to the same business group. Focusing on flows inside a given country helps to isolate networks effects from other determinants. In the same spirit as Wolf (2000) for the United States, there can be in our framework no room for explanations based on trade policy or on transaction costs associated with the use of different currencies, which both have been mentioned as possible important trade impediments.5 An additional novel aspect of our work is the use of "structural" specifications directly derived from a model of trade characterized by monopolistic competition, homebiased preferences, information and transport costs. This approach, following recent advances in gravity-type equations, is designed to reduce mis-specification and endogeneity issues. Within this vein, we present results along the lines of the fixed-effects approach à la Hummels (1999) and Redding and Venables (2004) and two different (though compatible) specifications based on Head and Mayer (2000) and Head and Ries (2001).

The rest of the paper proceeds as follows. Section 2 presents the theoretical model and the corresponding specifications to be estimated. The data used are described in Section 3. We separate our results in two sections. Section 4 evaluates the trade creating effects of business and social networks as estimated in specifications that consider only inter-regional trade flows and are thus fully comparable with existing work. Section 5 introduces the trade impact of administrative borders in the analysis. Using more sophisticated specifications, we quantify the impact of networks on all trade impediments, whether related to transport costs, borders or contiguity. Section 6 concludes.

\section{Theory and estimated specifications}

We describe in this section the theoretical underpinnings of the empirical specifications of trade flows we use. The modelling is inspired by the widely used trade model of monopolistic competition $\grave{a} l a$ Dixit-Stiglitz-Krugman (Dixit and Stiglitz, 1977; Krugman, 1980), slightly modified to account for home bias in consumers' preferences and transaction costs. ${ }^{6}$

\subsection{The fixed-effects approach}

\section{Consumption and trade flows}

The representative consumer's utility in region $i$ depends upon the consumption $c_{i j h}$ of all varieties $h$ produced in any region $j$. Varieties are differentiated with a constant elasticity of substitution (CES) but they do not enter symmetrically the utility function: A specific weight, $a_{i j}$, is attached to all varieties imported from region $j$, describing preferences of $i$ consumers with respect to $j$ varieties. Let $n_{j}$ denote the number of varieties produced in region $j$ and $N$ the total number of regions. The corresponding utility function is

$$
U_{i}=\left(\sum_{j=1}^{N} \sum_{h=1}^{n_{j}}\left(a_{i j} c_{i j h}\right)^{\frac{\sigma-1}{\sigma}}\right)^{\frac{\sigma}{\sigma-1}},
$$

where $\sigma>1$ is the elasticity of substitution. Let $p_{i j}$ denote the delivered price in region $i$ of any variety produced in region $j$. Denoting by $\tau_{i j}$ the iceberg-type ad valorem equivalent transaction cost between regions $j$ and $i$ and $p_{j}$ the mill price in $j$, we have $p_{i j}=\left(1+\tau_{i j}\right) p_{j}$. It is then straightforward

\footnotetext{
${ }^{5}$ See Rose (2000), Parsley and Wei (2001) and Taglioni (2002) for recent empirical evidence.

${ }^{6}$ Feenstra (2003) presents a complete overview of theoretical foundations and empirical estimations of trade-flow equations mainly focused on the monopolistic competition framework. Anderson and Van Wincoop (2003) and Eaton and Kortum (2002) are examples of alternative theoretical frameworks that also lead to structural estimations of trade flows.
} 
to obtain the following demand function

$$
c_{i j}=c_{i} P_{i}^{\sigma} n_{j} p_{j}^{-\sigma} a_{i j}^{\sigma-1}\left(1+\tau_{i j}\right)^{-\sigma},
$$

where $c_{i}=\sum_{j} \sum_{h} c_{i j h}$ is total consumption (in quantities ${ }^{7}$ in region $i$ of differentiated good varieties imported from all possible source regions (including $i$ ) and where $P_{i}$ is the price index in region $i$, $\left.P_{i} \equiv\left(\sum_{j} a_{i j}^{\sigma-1} n_{j} p_{i j}^{1-\sigma}\right)^{1 /(1-\sigma)}\right]_{8}^{8}$

Equation (2) links imports of region $i$ from region $j$ to the size of the demand expressed by the destination region $i\left(c_{i}\right)$, and its price index $\left(P_{i}\right)$, the size of the supply $\left(n_{j}\right)$ and the mill price of the origin region $j\left(p_{j}\right)$, and bilateral effects involving preferences $\left(a_{i j}\right)$ and transaction costs $\left(\tau_{i j}\right)$. There are two major problems that must be solved in order to obtain an estimable specification from equation (2). One must first deal with $P_{i}$, which complicates the estimation by introducing non linearity in unknown parameters. Next, the number of varieties produced in region $j, n_{j}$, and the mill prices, $p_{j}$, are usually not accurately measured and sometimes simply unobservable.

We consider three alternative strategies to tackle these issues.$^{9}$ First note that equation (2) involves three groups of variables: Origin ( $j$-specific), destination ( $i$-specific) and "dyadic" (or bilateral $i j$ specific) variables. When mostly interested in coefficients on dyadic variables, as is the case here, a first theory-consistent specification of equation (2) uses fixed effects for origin and destination regions to capture the first two groups of variables. This is the fixed-effects approach notably used by Hummels (1999) and Redding and Venables (2004) in similar theoretical settings. Next, we use two approaches which go further in the use of the theoretical framework to derive the specifications to be estimated. We call those the odds and friction specifications respectively. Presenting the details of these approaches will be easier after the specification of transaction costs $\left(\tau_{i j}\right)$ and of consumers' preferences $\left(a_{i j}\right)$.

\section{Transaction costs and preferences}

We consider two different elements in transaction costs: Physical transport costs, $T_{i j}$, and information costs, $I_{i j}$. We model transaction costs as follows:

$$
1+\tau_{i j}=T_{i j} I_{i j}
$$

Transport costs are assumed to have the structure

$$
T_{i j}=\left(1+t_{i j}\right)^{\delta} \exp \left(-\theta t_{i j}^{2}\right),
$$

where $t_{i j}$ is a measure of transport cost between $i$ and $j$ (detailed in section 3). With this specification, the absence of transport costs $\left(t_{i j}=0\right)$ would yield $T_{i j}=1$, which means that transaction costs would be entirely caused by information issues. Parameters $\delta$ and $\theta$ are expected to be positive. The quadratic cost function chosen embodies a standard feature of increasing returns in transport activities: The marginal cost of shipping a good is positive but it decreases with distance.

For the information cost, we assume

$$
I_{i j}=\left(1+\operatorname{mig}_{i j}\right)^{-\alpha_{I}}\left(1+\operatorname{mig}_{j i}\right)^{-\beta_{I}}\left(1+\operatorname{plant}_{i j}\right)^{-\gamma_{I}} \exp \left(\varphi_{I} A_{i j}-\psi_{I} C_{i j}\right) .
$$

\footnotetext{
${ }^{7}$ Those equations are usually presented in terms of the bilateral value of trade flows (equation 2 times $p_{i j}$ ). We work with trade flows in tons in the empirics and accordingly present the equations in quantity terms.

${ }^{8}$ Note that, with a production function $\grave{a}$ la Ethier (1982), the demand for inputs and therefore trade flows in intermediates take the same functional form, which is important as this type of shipments is a large share of total trade.

${ }^{9} \mathrm{~A}$ fourth strategy, and in fact the most usual approach, more or less ignores these problems, merely expecting that they will be of secondary order in the estimation, trade flows being overwhelmingly determined by the size of partners and a set of transaction costs proxies. For comparison purposes, we propose results using this standard gravity specification in the working paper version (Combes et al., 2004).
} 
$A_{i j}$ is a dummy variable set to 1 when $i \neq j$ and $C_{i j}$ is another dummy set to 1 when $i$ and $j$ are contiguous (but still different) regions. Our hypothesis is that $\varphi_{I}>0$ and $\psi_{I}>0$ : The informational transaction cost is lower inside a region than between two regions, but higher between two non-contiguous regions than between contiguous ones.

The impact of business and social networks on information costs is captured by three variables, $\operatorname{mig}_{i j}, \operatorname{mig}_{j i}$ and plant ${ }_{i j}$ corresponding to migrant and plant networks. Origin and destination subscripts of mig variables are chosen so that the historical movements of people underlying those variables follow the same direction as trade flows. Since $c_{i j}$ is the trade flow going from $j$ to $i, \operatorname{mig}_{i j}$ is the number of people born in region $j$ and working in region $i$, which corresponds to the cumulated flow of people that moved from $j$ to $i$ at some point in time and are still located there. We refer to the effect of mig $_{i j}$ as the effect of immigrants. Reciprocally, $\operatorname{mig}_{j i}$ is the effect of emigrants. Note the correspondence with the existing work on migration and trade surveyed in the introduction. We work here with a single trade matrix and two migration variables, whereas most of the existing work isolates imports from exports and thus uses two trade matrices but only one migration variable (estimating the impact of immigration on imports and exports).

Regarding our variable capturing networks of firms, we start by counting for each business group the number of plants located in each region $i, j, \ldots$. Then, we calculate for each dyad $i j$ the number of potential connections within the business group as being the product of its counts of plants in $i$ and $j$. We then sum this number over all business groups, which gives plant ${ }_{i j}$, our plant network variable. This variable, and therefore the impact of plant networks, is thus symmetric by construction, plant $_{i j}=$ plant $_{j i}{ }^{10}$ As stated in the introduction, migrant and plant networks are assumed to reduce information costs of trade shipments going both directions. Parameters $\alpha_{I}, \beta_{I}$, and $\gamma_{I}$ are therefore all expected to be positive.

Consumers are assumed to have both deterministic and stochastic elements in their preferences, $a_{i j}$. We assume systematic preferences for (i) local goods (produced in the region of consumption), (ii) goods produced in a contiguous region, and (iii) goods produced in the region where the consumer was born. This last effect is assumed to be increasing in the immigrants variable, $\operatorname{mig}_{i j}$ : Migrants partly bring their preferences for home products with them in the destination region and this pattern possibly propagates to the local consumers, raising the level of imports of the host region. Last, the random component in the preferences is denoted $e_{i j}$, and we assume the structure

$$
a_{i j}=\left(1+\operatorname{mig}_{i j}\right)^{\alpha_{a}} \exp \left[e_{i j}-\varphi_{a} A_{i j}+\psi_{a} C_{i j}\right],
$$

on preferences, with $\alpha_{a}, \varphi_{a}$ and $\psi_{a}$ being parameters, all expected to be positive. Immigrants can therefore have an effect on trade through both preference and information channels. Note that the effects are fundamentally different in both cases. For the preference part, the impact of migration corresponds to exogenous effects directly affecting the preferences of consumers. Concerning informational costs, they correspond to endogenous demand effects working in equilibrium through delivered prices that increase with transaction costs.

We now proceed to a presentation of the exact specifications that will be estimated and show how they relate to the theoretical expression of trade flows given in equation (2), combined with the specifications of transport costs (equation 4), information costs (equation 5), and preferences (equation 6).

\footnotetext{
${ }^{10}$ This relies on the implicit assumption that links between plants reduce the information cost symmetrically, that is they have the same impact on imports and exports. In Combes et al. (2004), we allow for possible asymmetries in the measure of plant connections.
} 


\section{The fixed-effects specification}

In the spirit of Hummels (1999) and Redding and Venables (2004) 11 it is possible to derive from equation (2) a fixed-effects specification fully consistent with the theoretical model. The idea consists in replacing all destination-specific and origin-specific variables by two groups of destination and origin fixed effects. Only dyadic variables are then left in the regression. We try to stay here as close as possible to the specifications estimated in the literature. We drop internal trade flows (no border effects), and use a simple log-linear effect of distance as a proxy for transport costs. Using the notations $x \equiv \sigma x_{I}+(\sigma-1) x_{a}$ for $x=\alpha$ and $\psi$, and $y \equiv \sigma y_{I}$, for $y=\beta$ and $\gamma$, this leads to the fixed-effects specification given by:

$$
\begin{aligned}
\ln \left(c_{i j}\right)= & f_{i}+f_{j}-b_{1} \ln \left(d_{i j}\right)+\psi C_{i j} \\
& +\alpha \ln \left(1+\operatorname{mig}_{i j}\right)+\beta \ln \left(1+\operatorname{mig}_{j i}\right)+\gamma \ln \left(1+\text { plant }_{i j}\right)+\epsilon_{i j} .
\end{aligned}
$$

where $f_{i}$ and $f_{j}$ are destination- and origin-region fixed effects respectively and $b_{1}$ is an extra parameter to be estimated. The main drawback of this approach is that it does not allow to estimate all structural parameters. In particular, the elasticity of substitution between varieties $(\sigma)$, which has been the subject of important academic interest in this type of analysis recently, cannot be recovered.

\subsection{The odds and friction specifications}

We now present specifications that permit broader identification of parameters. This requires to use theory further and makes use of a convenient feature of CES demand functions, emphasized in Anderson, de Palma and Thisse (1992) and often called the Independence of Irrelevant Alternatives (IIA) due to its similarity with the logit model. With this type of demand structure, the ratio of two bilateral trade flows to a same destination depends only on the characteristics of the two origins, which greatly simplifies the specification. ${ }^{12}$

\section{The Production Side of the Model}

Let $r$ denote a reference region. When imports of region $i$ from region $j$ are divided by imports of region $i$ from region $r$ (equation 2), one gets:

$$
\frac{c_{i j}}{c_{i r}}=\left(\frac{a_{i j}}{a_{i r}}\right)^{\sigma-1}\left(\frac{1+\tau_{i j}}{1+\tau_{i r}}\right)^{-\sigma}\left(\frac{p_{j}}{p_{r}}\right)^{-\sigma}\left(\frac{n_{j}}{n_{r}}\right) .
$$

While the price index does not enter the equation anymore, one still has to deal with numbers of varieties and mill prices. It is possible, however, to use the behavior of producers under monopolistic competition to obtain a correspondence with variables that are easier to observe, namely regional production and wages. As usual in this type of model, it is assumed that differentiation costs are sufficiently low to ensure that each variety is produced by a single firm with an increasing returns to scale technology common to all regions and using labor as the only input.

The Dixit-Stiglitz-Krugman model of monopolistic competition assumes that firms are too small to have a sizeable impact on the overall price index and on the regional income when they set their price to maximize profits. This yields the standard constant markup over marginal cost pricing rule, $p_{j}=\frac{\sigma}{\sigma-1} g w_{j}$, where $w_{j}$ is the wage rate in region $j$ and $g$ the unit labor requirement. Consequently,

\footnotetext{
${ }^{11}$ Harrigan (1996) seems to be one of the first to have used fixed effects in the estimation of a monopolistic competition model of bilateral trade flows.

${ }^{12}$ The main interest of this approach is to solve the issue of the highly non linear price index term in estimation. Head and Mayer (2000) and Eaton and Kortum (2002) also use this property of the CES function to obtain their estimable trade equation. Lai and Trefler (2002) and Anderson and van Wincoop (2003) have different empirical approaches of the same issue involving non linear estimation techniques.
} 
all varieties produced in region $j$ have the same mill price. The zero profit condition gives the equilibrium output of each firm, which is the same in all regions, and is noted $q$. Let $v_{j}$ denote the value of the total production in region $j$, we obtain $v_{j}=n_{j} p_{j} q$. Therefore, using the pricing rule, $n_{j} / n_{r}=\left(v_{j} w_{r}\right) /\left(v_{r} w_{j}\right)$. Using the definition of the delivered prices and the pricing rule, equation (8) can be rewritten as

$$
\frac{c_{i j}}{c_{i r}}=\left(\frac{a_{i j}}{a_{i r}}\right)^{\sigma-1}\left(\frac{1+\tau_{i j}}{1+\tau_{i r}}\right)^{-\sigma}\left(\frac{w_{j}}{w_{r}}\right)^{-(\sigma+1)} \frac{v_{j}}{v_{r}} .
$$

\section{The odds specifications}

Replacing in equation (9) the different specifications we assume for the transaction cost (equations 3 to 5) and the preferences (equation 6), we obtain what we call the odds specification

$$
\begin{aligned}
\ln \left(\frac{c_{i j}}{c_{i r}}\right)= & \phi \ln \left(\frac{v_{j}}{v_{r}}\right)-(\sigma+1) \ln \left(\frac{w_{j}}{w_{r}}\right)-\sigma \delta \ln \left(\frac{1+t_{i j}}{1+t_{i r}}\right)+\sigma \theta\left(t_{i j}^{2}-t_{i r}^{2}\right) \\
& +\alpha \ln \left(\frac{1+\operatorname{mig}_{i j}}{1+\operatorname{mig}_{i r}}\right)+\beta \ln \left(\frac{1+\operatorname{mig}_{j i}}{1+\operatorname{mig}_{r i}}\right)+\gamma \ln \left(\frac{1+\operatorname{plant}_{i j}}{1+\operatorname{plant}_{i r}}\right) \\
& -\varphi\left(A_{i j}-A_{i r}\right)+\psi\left(C_{i j}-C_{i r}\right)+\epsilon_{i j},
\end{aligned}
$$

where $\varphi \equiv \sigma \varphi_{I}+(\sigma-1) \varphi_{a}$. The fact that $\epsilon_{i j}=(\sigma-1)\left(e_{i j}-e_{i r}\right)$ implies that errors are not independently distributed. This correlation is accounted for in the estimation through a robust clustering procedure, allowing residuals of the same importing region to be correlated. The theoretical framework predicts $\phi=1 . \phi$ is a parameter introduced in the odds specification in order to give additional flexibility in the estimations. The results regarding the impact of business and social networks are virtually unaffected by this standard variant of the model. Furthermore, we propose below another specification that bypasses the estimation of this coefficient.

We actually estimate two different odds specifications. The complete odds specification takes the internal flow or "imports from self" as a reference, that is, it assumes $r=i$ in equation (10). This amounts to dividing each inter-regional flow by the corresponding internal flow of the importer. Then, since only the $i \neq j$ observations are kept in the regression, $-\varphi\left(A_{i j}-A_{i i}\right)=-\varphi$, which is the constant of the model and provides an estimate of the effect of administrative borders on trade volumes in France. The complete odds specification is:

$$
\begin{aligned}
\ln \left(\frac{c_{i j}}{c_{i i}}\right)= & \phi \ln \left(\frac{v_{j}}{v_{i}}\right)-(\sigma+1) \ln \left(\frac{w_{j}}{w_{i}}\right)-\sigma \delta \ln \left(\frac{1+t_{i j}}{1+t_{i i}}\right)++\sigma \theta\left(t_{i j}^{2}-t_{i i}^{2}\right) \\
& +\alpha \ln \left(\frac{1+\operatorname{mig}_{i j}}{1+\operatorname{mig}_{i i}}\right)+\beta \ln \left(\frac{1+\operatorname{mig}_{j i}}{1+\operatorname{mig}_{i i}}\right)+\gamma \ln \left(\frac{1+\operatorname{plant}_{i j}}{1+\operatorname{plant}_{i i}}\right) \\
& -\varphi+\psi C_{i j}+\epsilon_{i j} .
\end{aligned}
$$

We also estimate what we call the basic odds specification that does not use internal trade flows (and thus does not consider border effects). For each destination $i$ the reference region ( $r$ in equation 10 is chosen to be the origin region with the largest flow to region $i$. Last, we maintain for the basic odds specification the same approximation of transport costs by bilateral distance as in the fixed-effects specification.

\section{The friction specification}

Finally, following Head and Ries (2001), we estimate a specification which goes one step further in using the IIA property of the CES. An inverse index of "frictions" to trade, often referred to as a 
freeness of trade index, can be defined as

$$
\Phi_{i j}=\sqrt{\frac{c_{i j}}{c_{i i}} \frac{c_{j i}}{c_{j j}}}
$$

Using equation (11), and assuming that $t_{i j}=t_{j i}$, we obtain the friction specification:

$$
\begin{aligned}
\ln \left(\Phi_{i j}\right)= & -\sigma \delta \ln \left(\frac{1+t_{i j}}{\sqrt{\left(1+t_{i i}\right)\left(1+t_{j j}\right)}}\right)+\sigma \theta\left[t_{i j}^{2}-\frac{t_{i i}^{2}}{2}-\frac{t_{j j}^{2}}{2}\right] \\
& +(\alpha+\beta) \ln \left(\sqrt{\frac{\left(1+\operatorname{mig}_{i j}\right)\left(1+\operatorname{mig}_{j i}\right)}{\left(1+\operatorname{mig}_{i i}\right)\left(1+\operatorname{mig}_{j j}\right)}}\right)+\gamma \ln \left(\frac{1+\text { plant }_{i j}}{\sqrt{\left(1+\operatorname{plant}_{i i}\right)\left(1+\text { plant }_{j j}\right)}}\right) \\
& -\varphi+\psi C_{i j}+\varepsilon_{i j} .
\end{aligned}
$$

The friction specification has the advantage of being compatible with the strict version of the model implying $\phi=1$. Importantly, it does not require data on regional values of production $\left(v_{i}\right)$ and wages $\left(w_{i}\right)$, which is a noticeable advantage considering the measurement errors and missing values often found in those series as well as the likely endogeneity issues associated with these variables. Again, spatial autocorrelation introduced by the fact that $\varepsilon_{i j}=\frac{1}{2}\left(\epsilon_{i j}+\epsilon_{j i}\right)$ is taken into account in estimation.

Unfortunately, none of the four specifications allows for an identification of all structural parameters (for instance, the preference component $\alpha_{a}$ cannot be estimated separately from its information counterpart $\alpha_{I}$ in the total effect of immigrants, $\alpha$ ). However, some rough inference can be made: If emigrants have a larger impact on trade than immigrants, one can conclude that the effect of preferences is sufficiently weak to be dominated by the information effect of migrants on exports even when the information effect on imports adds to the diffusion of preferences. Gould (1994), Girma and $\mathrm{Yu}$ (2002) or Wagner et al. (2002) follow this strategy when comparing the impact of immigrants on imports and exports. Similarly, since networks of plants presumably do not encompass any preference effects, a larger estimate of those compared to the coefficients on migrants means that the pure information effect of business networks between plants is stronger than the combined effect of information and preferences due to migrants networks ${ }^{13}$

\section{Data}

The data needed to estimate the specifications just described consist in bilateral trade flows, regional production and wages, bilateral measures of transport costs and of business and social networks. Our sample covers trade between and within French regions for the year 1993. Regions are defined according to the administrative division of continental France into 94 units called "départements". The spatial organization of France in départements was introduced simultaneously with the elaboration of the first French constitution (there were 83 départements in the original bill voted in 1790). Interestingly, the original design of this key reform of French administration accompanying the change of political regime was concerned with economic motivations, and more precisely transportation issues: The size of each département would have to be such that it would be possible from any point inside the département to reach its capital city (usually centrally located) and come back within 48 hours. This meant, at a time when horses were the fastest mean of transport, départements organized within a radius of 30 to 40 kilometers around their capitals.

Even today, départements probably represent meaningful lines of demarcation inside France for both economic activity and networks. One of the reasons for this is that départements have been

\footnotetext{
${ }^{13}$ Combes et al. (2004) elaborate more on these non-trivial identification issues.
} 
given important attributions, with corresponding budgetary transfers, by the "decentralization laws" of 1982-1983 ${ }^{14}$ The central government provided the financial means of this policy through $(i)$ the direct funding of each département's budget and ( $i i)$ through transfers of direct and indirect local tax instruments on which the département has full authority (this part represents the majority of receipts in the budget of départements, see Ministry of the Interior (DGCL), 2003, for details). The elected executive power of each département thus has a substantial impact on the local economy through its fiscal and tax policies ${ }^{15}$ In parallel, business and social networks are likely to be at least partly organized around the natural delimitations that départements represent. Although it is hard to capture precisely something like the density and spatial extent of networks, an example of this phenomenon is the spatial organization of the chambers of commerce and industry in France. Each département has usually one such chamber (the départements with the largest cities or industrial bases have usually two), taking the name of the département. Those chambers have the official role of representing the "commercial and industrial interests of their jurisdiction" to the public authorities and are elected by the local business community. They notably provide services to local firms in terms of administrative procedures for the creation of a firm, data and expertise on local markets and potential suppliers, relationships with local authorities. They are consulted in the making of local public policies on numerous economic-related subjects. Moreover, those chambers officially administrate 121 airports, 180 ports, more than 300 educational establishments (and notably a large number of business schools) and 55 exposition halls (ACFCI, 2002). These institutions are an example of why départments can constitute relevant geographical units for the establishment and maintenance of networks in France.

\section{Trade, production and wages}

Trade flows between and inside regions come from the French Ministry of Transports database on commodity flows. The source and construction method of these data are comparable to the U.S. Commodity Flow Survey (CFS) recently used in Wolf (2000), Anderson and van Wincoop (2003) or Hillberry and Hummels (2003) for instance. The data is based on an annual survey of a stratified random sample of vehicles from the road transport industry to which the exhaustive collection of trade flows shipped by railway is added.

The dataset includes both inter- and intra-regional flows and is originally available at a very detailed industry level. However, the number of observations being low for some industries, we aggregate the flows over all industries. This data set suffers from the same imperfections as the CFS concerning the way loading and unloading are handled. The main issue is the statistical collection of actual origins and destinations of shipments that transit through warehouses or ports for instance where they are unloaded and later re-loaded on an often different truck or mode. Those issues can result in a distorted image of actual trade patterns. It has been notably shown by Hillberry and Hummels (2003) that shipments originating from wholesalers cover a much lower distance that shipments from manufacturers, reflecting hub and spoke arrangements in distribution. Those short-distance flows from wholesalers to retailers contribute to inflate the amount of trade taking place within the administrative borders of American states and their estimated trade-reducing effect. Besides, while both the CFS and our dataset try to sort out flows that are only in transit in a region, a large amount of shipments to and from major ports is admitted to be in reality transit shipments. The corresponding origin region then appears to be an excessive source of flows compared to its real production (and reciprocally as destination). One way, consistent with theory, to mitigate this problem is to consider regional production (computed as the sum of the flows departing from the region including the internal flow)

\footnotetext{
${ }^{14}$ The most important of those attributions concern social aid actions, the construction and operation costs of the 4 first years of secondary schools ("collèges", with the exception of personnel salaries), and the construction and maintenance costs of part of the roads (a substantial part in rural areas).

${ }^{15}$ The overall fiscal expenditures of départements in 2003 are around 47 billion euros against a predicted 273 billions for the French central government.
} 
instead of GDP as the origin size variable. Similarly, the size of the destination region can be computed as the sum of all flows to the region instead of the regional GDP ${ }^{16}$ The fixed-effects approach is another way to account for those transit flows since the dummy variable for a given region will capture the fact that this region appears to import or export too much compared to its GDP. Last, labor costs are proxied by dividing the annual regional wage bill by the regional number of workers. This computation uses the "Enquête Annuelle d'Entreprises" survey (EAE) from the French National Institute of Statistics and Economic studies (INSEE).

\section{Distance and transport costs}

The theoretical model requires the use of a measure of transport costs between and within French regions. Most studies investigating trade determinants use great circle distance as a proxy for those costs. In order to make the comparison with previous papers easier, our fixed-effects and basic odds specifications are also estimated using distance, but real road distance between the main cities of the two partner regions.

For the complete odds and the friction specifications, we follow a recent trend in the literature that uses newly available data on actual transport costs (see for instance Hummels, 1999, Limão and Venables, 2001). We use the Combes and Lafourcade (2004) data set that provides the cost for a truck to connect each pair of French regions. This generalized transport cost includes both a cost per kilometer (gas, tolls,...) and a time opportunity cost (drivers' wages, insurance,...), and therefore accounts for both distance and time-related transport costs (see Combes and Lafourcade, 2004, for more details). The estimation of the complete odds and friction specifications also requires an intraregional transport cost for which no data exist in France. We construct those by first regressing transport costs on real road distances and then applying estimated coefficients to internal distances in order to obtain the corresponding internal transport costs. The internal distance is obtained using the standard approximation that each region is a disk upon which all production concentrates at the center and consumers are uniformly distributed throughout a given proportion of the total land-area of the region. We choose this proportion to be equal to $\frac{1}{16}$, which is a reasonable approximation of the observed concentration of population in France ${ }^{17}$ The internal distance formula is thus given by $d_{i i}=1 / 6 \sqrt{A / \pi}=0.094 \sqrt{A}$ where $A$ is the regional land-area.

\section{Business and social networks}

The migrant network variables correspond to the number of people working in the destination region who were born in the origin region (and the reverse). They are thus bilateral stock variables computed using the Déclaration Annuelle the Données Sociales survey (DADS) collected by INSEE ${ }^{18}$ The plant network variable uses the number of plants belonging to the same business group in both the origin and destination regions. A business group has a larger definition than a firm (itself potentially incorporating several plants). For instance, all plants of the two car-producing firms Peugeot and Citroën belong to the same business group called PSA. The precise definition of a business group is the set of firms controlled directly or indirectly by a given firm, itself not controlled by any other. The definition of control is the ownership of more than $50 \%$ of the votes in the shareholders' committee. Both migrants and business groups network variables are calculated using 1993 data, the same year as trade flows.

\footnotetext{
${ }^{16}$ Results using GDPs are available upon request. Our primary interest results, coefficients on network effects, are virtually unaffected.

${ }^{17}$ INSEE (2001) reports that more than $80 \%$ of the French area was occupied by agricultural land in 1999 and that $77 \%$ of the population lived in urban areas.

${ }^{18}$ The DADS survey includes a representative $1 / 24^{t h}$ of the French population (all French citizens born in October of even years). See Abowd et al. (1999) for a detailed description of this data).
} 
Table 1: Summary statistics

\begin{tabular}{l|cccc}
\hline \hline Variable & Mean & Sdt. Dev. & Min & Max \\
\hline flows (tons) & 68,883 & 221,971 & 1 & $8,012,491$ \\
production (1,000 tons) & 14,600 & 9,072 & 1,367 & 49,800 \\
consumption (1,000 tons) & 14,500 & 8,762 & 2,169 & 47,800 \\
wages (1,000 ECUs/year) & 23.1 & 2.1 & 20.1 & 33.0 \\
distance (kms) & 459.2 & 229.3 & 11 & 1,282 \\
transport costs (French francs) & $2,666.6$ & $1,206.7$ & 290.2 & $6,966.8$ \\
immigrants (\# persons) & 28.8 & 141.3 & 0 & 7,332 \\
emigrants (\# persons) & 28.7 & 141.3 & 0 & 7,332 \\
plant links (prod. of \# plants) & 203.0 & 309.2 & 0 & 4,481 \\
\hline
\end{tabular}

Note: Statistics calculated for the sample used in section[4 and consisting of interregional flows only (omitting the 94 observations where $i=j$ ). The construction of the migrant network variables implies that variables at origin and at destination have identical distributions since each $i j$ observation has a corresponding $j i$ one taking the same value. The mean values are not exactly identical here however since only non-zero inter-regional trade flows are kept, which excludes $14.8 \%$ $(1,251 / 8,742)$ of the observations and makes the sample slightly asymmetric.

Table 1 gives summary statistics for the data we use. Since the average of the migrant variables in the DADS survey is around 29, we approximately expect an average of 700 persons born in a given region and living in another one. This corresponds to an average share of migrants in region $i$ born in region $j$ around $0.5 \%$. Correspondingly, it is possible to compute that the share of people still working in the region where they were born is on average $52.6 \%$.

On average, the number of plant connections between two different regions is 203, against 922 within the same region. Thus, as for migrant networks, but to a smaller extent, the proxy for plant networks presents the feature of much higher values for intra-regional observations: A ratio of 4.5, against 87 for immigrants. This can be usefully compared to an average ratio of intra-regional over inter-regional trade flows of more than a hundred (8,220,683 against 68,883 tons) 19

Table 2: Correlation matrix

\begin{tabular}{l|ccccccccc}
\hline \hline & $(1)$ & $(2)$ & $(3)$ & $(4)$ & $(5)$ & $(6)$ & $(7)$ & $(8)$ & $(9)$ \\
\hline flows (1) & 1 & $0.18^{*}$ & $0.17^{*}$ & $0.09^{*}$ & $-0.33^{*}$ & $-0.34^{*}$ & $0.42^{*}$ & $0.45^{*}$ & $0.31^{*}$ \\
production at orig. (2) & & 1 & $-0.05^{*}$ & $0.31^{*}$ & $0.12^{*}$ & $0.10^{*}$ & $0.07^{*}$ & $0.08^{*}$ & $0.38^{*}$ \\
consumption at dest. (3) & & & 1 & -0.02 & $0.11^{*}$ & $0.09^{*}$ & $0.09^{*}$ & $0.08^{*}$ & $0.38^{*}$ \\
wages at orig. (4) & & & & 1 & -0.02 & $-0.04^{*}$ & $0.16^{*}$ & $0.26^{*}$ & $0.42^{*}$ \\
distance (5) & & & & & 1 & $0.99^{*}$ & $-0.18^{*}$ & $-0.18^{*}$ & $-0.03^{*}$ \\
transport costs (6) & & & & & & 1 & $-0.18^{*}$ & $-0.18^{*}$ & $-0.05^{*}$ \\
immigrants (7) & & & & & & & 1 & $0.44^{*}$ & $0.42^{*}$ \\
emigrants (8) & & & & & & & & 1 & $0.42^{*}$ \\
plant links (9) & & & & & & & & & 1 \\
\hline
\end{tabular}

Note: ${ }^{*}$ denotes significantly different from 0 at the $1 \%$ level.

Table 2 presents the simple correlations between all variables. The correlations between flows and network variables are large. Flows and migrant networks are also strongly negatively correlated with distance or transport costs. As detailed in Combes and Lafourcade (2004), the correlation between bilateral distance and transport costs is very large in cross-section, which we also get here. Last, a positive correlation between all network variables is also observed.

\footnotetext{
${ }^{19}$ Note also that the average flow inside a départment is higher than the maximal flow between two different regions in our sample.
} 
Figure 1: Number of immigrants $\left(\mathrm{mig}_{i j}\right.$, left panel) and of plant connections ( plant $_{i j}$, right panel), for Paris (top), Rhône (middle) and Bouches-du-Rhône (bottom)
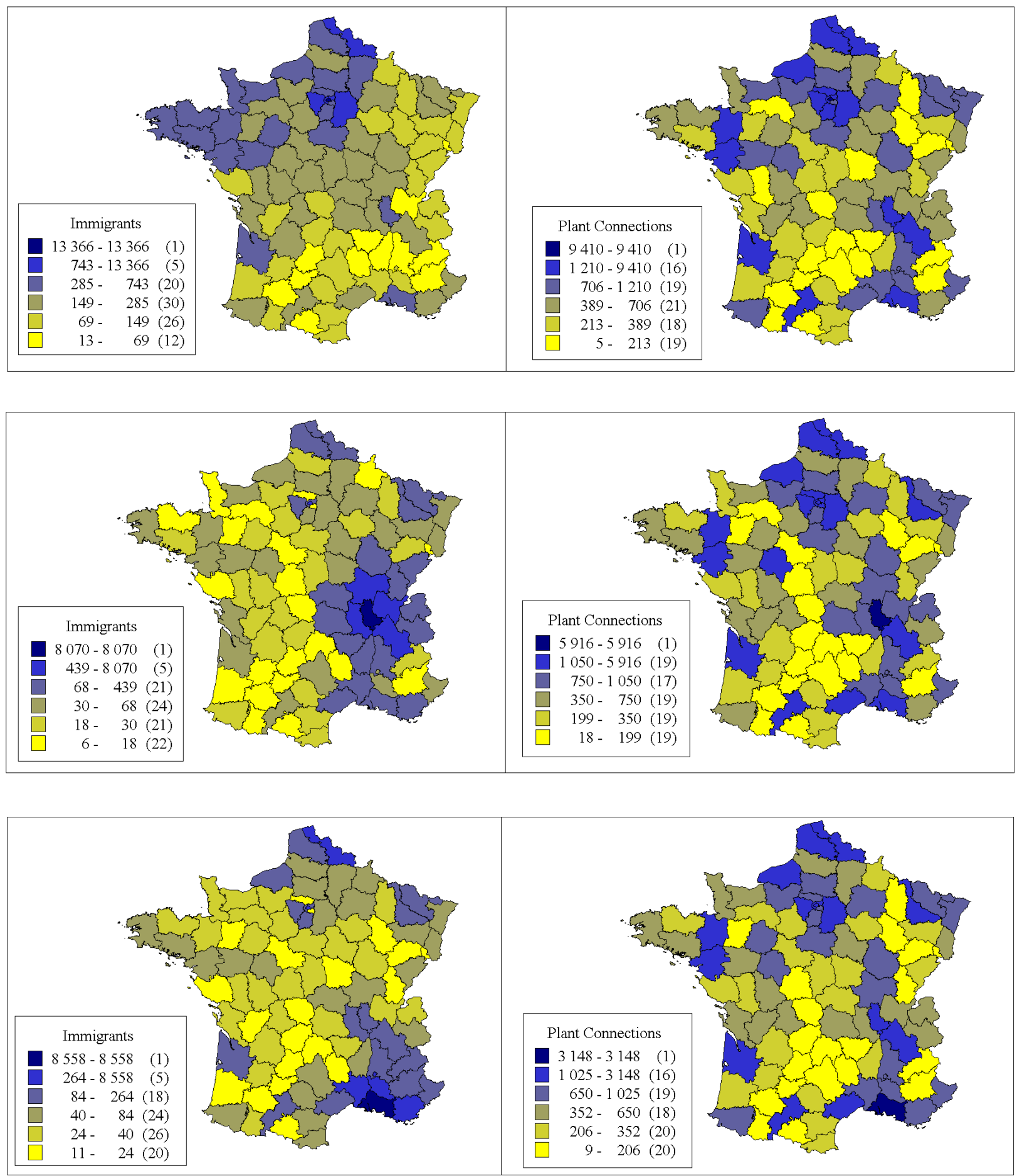
Figure 1 helps further the understanding of these correlations and, more generally, of the spatial patterns of network variables. The left-hand side maps correspond to the immigrants networks and the right-hand side to counts of plant connections. Each pair of maps corresponds to one of the destination département hosting the three largest French cities: Paris (top pair), Rhône (Lyon, middle pair) and Bouches-du-Rhône (Marseille, bottom pair). For each map, the highest class is colored in black and only includes the region to which the map refers, which facilitates its location.

The top left map shows that Paris hosts large numbers of migrants originating from regions either relatively proximate to Paris (North, North-West of France), or more remote but larger in terms of population (the regions hosting Bordeaux, Lyon and Marseille notably). This gravity pattern also clearly emerges for Rhône and Bouches-du-Rhône. The effect of distance is still strong but large regions as Paris or Nord appear as major sources of migrants. Regarding plant links, the impact of distance is less striking. The size of the origin region, however, still has a clear role, the spatial pattern of plant networks being quite similar independently from the destination region. Levels change, however. This conclusion is confirmed by the relatively large correlation between plant links and production (see Table 2).

\section{The trade creating effect of business and social networks}

This section evaluates the statistical significance and economic magnitude of the impact of business and social networks on trade flows. Results are presented omitting intra-regional trade observations, and therefore abstracting from the analysis of border effects, covered in the next section.

\section{Significance and explanatory power of network variables}

Tables 3 and 4 report the estimations for the fixed-effects and the basic odds specifications, respectively. The structure of these tables is the same. Column (1) reports the estimates without network variables. Migrant effects are introduced one by one in columns (2) and (3) and simultaneously in column (4). Column (5) reports the effect of plant networks. Last, column (6) reports results considering all network effects together.

Table 3 reveals expected coefficients on traditional trade impediments variables, distance and contiguity. The estimated impact of distance is larger (in absolute value) than usually found. A plausible explanation is that our sample exclusively incorporates flows transiting through ground transport means, which has been shown by Disdier and Head (2003) to yield substantially higher distance coefficients. They show in a meta-analysis of distance coefficients in gravity equations that papers involving countries belonging to a single continent have distance coefficient about 0.4 above the average distance effect estimate. Note also that the distance coefficient gets back to more usual values (around minus unity) when using the basic odds specification.

Concerning the network effects we are primarily interested in, a first overall conclusion to be drawn from Tables 3 and 4 is that the impact of business and social networks is consistent with theoretical predictions and qualitatively similar in all specifications used. All network variables have a positive and very significant impact on trade flows in the two specifications.

In terms of explanatory power, we obtain the expected result that the fixed-effects approach improves the fit compared to the basic odds specification. First, all variables being computed as differences with respect to the reference region, the variance to be explained is larger in basic odds than in fixed-effects. The former specification mechanically reduces the explanatory power of the model, very much as when first-difference estimations are performed in time-series compared to estimations in levels. Second, the fixed-effects specification introduces more flexibility in the estimation, as it does not constrain the origin and destination regions' influence to be strictly proportional to production

and wages. By contrast, while $\mathrm{R}^{2}$ gains are fairly small when network variables are introduced in the fixed-effects regressions, they are more substantial in the basic odds specification. This underlines 
Table 3: Fixed-effects specification

\begin{tabular}{l|cccccc}
\hline \hline \multirow{3}{*}{ Model : } & \multicolumn{6}{|c}{ Dependent variable: Flow } \\
\cline { 2 - 7 } distance & $(1)$ & $(2)$ & $(3)$ & $(4)$ & $(5)$ & $(6)$ \\
& $\left(0.76^{a}\right.$ & $-1.55^{a}$ & $-1.49^{a}$ & $-1.40^{a}$ & $-1.68^{a}$ & $-1.37^{a}$ \\
contiguity & $(0.09)$ & $(0.07)$ & $(0.09)$ & $(0.06)$ & $(0.08)$ \\
& $0.98^{a}$ & $0.63^{a}$ & $0.53^{a}$ & $0.39^{a}$ & $0.91^{a}$ & $0.38^{a}$ \\
& $(0.07)$ & $(0.08)$ & $(0.09)$ & $(0.09)$ & $(0.07)$ & $(0.09)$ \\
immigrants & & $0.25^{a}$ & & $0.16^{a}$ & & $0.14^{a}$ \\
& & $(0.05)$ & & $(0.04)$ & & $(0.04)$ \\
emigrants & & & $0.33^{a}$ & $0.27^{a}$ & & $0.26^{a}$ \\
& & & $(0.04)$ & $(0.04)$ & & $(0.04)$ \\
plant links & & & & & $0.30^{a}$ & $0.23^{a}$ \\
& & & & & $(0.05)$ & $(0.05)$ \\
\hline $\mathrm{N}$ & 7,491 & 7,491 & 7,491 & 7,491 & 7,491 & 7,491 \\
$\mathrm{R}^{2}$ & 0.611 & 0.615 & 0.617 & 0.619 & 0.614 & 0.620 \\
RMSE & 1.300 & 1.294 & 1.290 & 1.288 & 1.296 & 1.285 \\
\hline
\end{tabular}

Notes: (i) All variables in logarithm (except the contiguity dummy): See equation (7). (ii) Importer and exporter specific dummy variables included. (iii) Robust standard errors in brackets. ${ }^{a},{ }^{b},{ }^{c}$ : Significance at the $1 \%, 5 \%$, $10 \%$ levels, respectively.

Table 4: Basic odds specification

\begin{tabular}{l|cccccc}
\hline \hline \multirow{3}{*}{ Model : } & \multicolumn{6}{|c}{$\begin{array}{l}\text { Dependent Variable: Bilateral } \\
\text { flow from reference region }\end{array}$} \\
\cline { 2 - 7 } intercept & $(1)$ & $(2)$ & $(3)$ & $(4)$ & $(5)$ & $(6)$ \\
\hline \multirow{4}{*}{ distance } & $-2.62^{a}$ & $-2.16^{a}$ & $-2.04^{a}$ & $-1.95^{a}$ & $-2.45^{a}$ & $-1.98^{a}$ \\
& $(0.15)$ & $(0.15)$ & $(0.14)$ & $(0.15)$ & $(0.13)$ & $(0.15)$ \\
contiguity & $-1.01^{a}$ & $-0.79^{a}$ & $-0.80^{a}$ & $-0.73^{a}$ & $-0.95^{a}$ & $-0.74^{a}$ \\
& $(0.09)$ & $(0.10)$ & $(0.10)$ & $(0.10)$ & $(0.08)$ & $(0.09)$ \\
production & $2.00^{a}$ & $1.56^{a}$ & $1.50^{a}$ & $1.39^{a}$ & $1.84^{a}$ & $1.42^{a}$ \\
& $(0.13)$ & $(0.13)$ & $(0.11)$ & $(0.12)$ & $(0.11)$ & $(0.12)$ \\
wage & $0.80^{a}$ & $0.60^{a}$ & $0.64^{a}$ & $0.57^{a}$ & $0.43^{a}$ & $0.36^{a}$ \\
& $(0.08)$ & $(0.09)$ & $(0.08)$ & $(0.08)$ & $(0.10)$ & $(0.10)$ \\
immigrants & $-1.76^{a}$ & $-0.89^{b}$ & $-3.08^{a}$ & $-1.96^{a}$ & $-3.35^{a}$ & $-2.78^{a}$ \\
& $(0.47)$ & $(0.37)$ & $(0.48)$ & $(0.43)$ & $(0.58)$ & $(0.53)$ \\
emigrants & & $0.30^{a}$ & & $0.21^{a}$ & & $0.19^{a}$ \\
& & $(0.06)$ & & $(0.07)$ & & $(0.07)$ \\
plant links & & & $0.32^{a}$ & $0.19^{a}$ & & $0.12^{b}$ \\
& & & $(0.05)$ & $(0.05)$ & & $(0.05)$ \\
$\mathrm{N}$ & & & & & $0.46^{a}$ & $0.31^{a}$ \\
$\mathrm{R}^{2}$ & 7,491 & 7,491 & 7,491 & 7,491 & 7,491 & 7,491 \\
RMSE & 0.366 & 0.393 & 0.391 & 0.400 & 0.390 & 0.410 \\
\hline
\end{tabular}

Notes: $(i)$ All variables in logarithm and computed relatively to the origin corresponding to the highest flow with the destination (except the contiguity dummy): See equation (10). (ii) Robust standard errors in brackets. ${ }^{a},{ }^{b},{ }^{c}$ : Significance at the $1 \%, 5 \%, 10 \%$ levels, respectively. 
two points. First, network effects substitute to the effects of traditional trade impediments more than they explain a new part of the variance of flows in both specifications, a point we detail in section 5 . Second, the specification of explanatory variables in strict accordance with theory in the basic odds specification makes those more orthogonal to each other, which allows a better identification of the effect of networks.

These results all point to the conclusion that business and social networks exert a very significant positive impact on trade. The similarity of the results is quite striking between those two fairly different approaches. Network links created by both migrants and business groups appear to enhance trade. Last, the effects are shown to be at work in both directions. In region $i$, the migrants from region $j$ or the links with plants in region $j$ would favor both imports from and exports to region $j$.

\section{The magnitude of the trade creating effect of networks}

Beyond the significance of network effects, even more important is the assessment of their magnitude and thus of their economic importance. Network effects could well be significant but simultaneously not account for a large share of trade. Rauch and Trindade (2002) propose to compute the share of trade created by ethnic Chinese populations. Following their method, we compute the impact on trade of all network variables, which is given by:

$$
\left(\overline{1+z_{i j}}\right)^{\widehat{\varrho}},
$$

where $\overline{1+z_{i j}}$ is the average value taken by each network variable $\left(z_{i j}=\operatorname{mig}_{i j}, \operatorname{mig}_{j i}\right.$, plant $\left.{ }_{i j}\right)$ and $\widehat{\varrho}$ the estimate of the corresponding elasticity. Results reported in Table 5 can be read as follows. Each line corresponds to the specification mentioned. Columns labelled "Separate" ("Simultaneous", respectively) report the impact on trade of network variables when they are introduced in the regression separately (simultaneously, respectively). For instance, the first figure in line "Fixed-effects" (column "Separate" / "Immigrants") means that immigrants increase trade by $73.3 \%$, as calculated from the average value of that variable and the coefficient of a fixed-effects estimation in which this is the only network variable considered (Table 3, column (2)) .

Table 5: Trade creation (in \%)

\begin{tabular}{l|c|c|c|c|c|c}
\hline \hline & \multicolumn{3}{|c|}{ Separate } & \multicolumn{3}{c}{ Simultaneous } \\
\cline { 2 - 7 } & Immigrants & Emigrants & Plant links & Immigrants & Emigrants & Plant links \\
\hline Fixed-effects & 73.3 & 102.3 & 303.4 & 36.6 & 73.8 & 192.5 \\
Basic odds & 91.9 & 99.2 & 719.9 & 52.5 & 30.0 & 320.7 \\
\hline
\end{tabular}

Note: Percentage of trade increase computed as given in equation (14).

To summarize results, we show that the impact of network variables is: $(i)$ larger when variables are introduced separately than when introduced simultaneously, $(i i)$ slightly stronger in the basic odds specification than in the fixed-effects, (iii) generally stronger for plant networks than for migrant networks. Conclusion $(i)$ is quite intuitive, since network variables are positively correlated with each other (see Table 2) and tend to partially exclude each other when introduced simultaneously. We attribute conclusion (ii) to the fact that the estimated relationship has a better specification in the basic odds specification, which improves the estimation of network effects. Conclusion (iii) is a new result: Business networks across locations associated with economic links between plants have a substantially higher impact on trade than networks based on migrant connections.

Interestingly, the impact of migrants alone is found to be of the same order of magnitude as the one estimated by Rauch and Trindade (2002) for ethnic Chinese populations. The product of Chinese population shares at origin and destination increase trade in a gravity specification by $60 \%$. The 
effects of migration, either immigrants or emigrants, within France, range from $73.3 \%$ to $102.3 \%$, a level that is slightly stronger than the effect of Chinese populations on international trade. The economic impact of business networks between plants is found to be generally much larger than the impact of migrants. To the best of our knowledge this had never been econometrically quantified. When introduced separately from the migrants, according to the fixed-effects estimation, links between plants belonging to the same business group would make trade around four times larger than in the absence of network effects (around eight times larger in the basic odds specification). These are large numbers.

However, using a single variable to proxy network effects might capture the impact of other missing network variables. In order to correctly quantify the impact of each variable, it is thus more consistent to use regressions where all variables are introduced simultaneously. According to the fixed-effects or the basic odds specifications, when controlling for plant networks, the impact of each migrant variable is lower than when introduced alone, but still not negligible: Each kind of migrant variable creates between $30.0 \%$ and $73.8 \%$ of inter-regional trade, while both kinds together increase trade by $36.6+73.8=110.4 \%$ in the fixed-effects specification and $52.5+30.0=82.5 \%$ in the basic odds specification. One can therefore conclude that in France, the presence of migrants (from other French regions) roughly doubles inter-regional trade on average, compared to an hypothetical situation without any mobility of people. The impact of plant networks is lower than when entered in the regression separately from migrant networks. Still, plant networks multiply trade by nearly three in fixed-effects and more than four in basic odds.

Finally, note that it is difficult to state which of the impacts of immigrants or emigrants is larger. Results on this question vary depending on the considered variable and on the way the effect is estimated. This is probably due to the collinearity between network variables. It is therefore difficult to compare the relative magnitude of the preference effects of networks to their information counterpart using the comparison of immigrants' and emigrants' coefficients. However, as proposed above, the use of plant networks here helps in this identification process. The much larger effect of plant networks points to a dominance of information effects over preference effects.

\section{Can networks explain the border effect puzzle?}

We now turn to the estimation of the last two specifications we propose. They both allow to estimate the effect of administrative borders in France, identified as the average ratio between intra- and interregional trade flows. This can thus be viewed as a way to properly assess the impact of networks on all trade impediments (as opposed to focusing on barriers taking place between regions only captured by distance and contiguity). The main difference between the basic and the complete odds specifications relies on the fact that the reference flow is the internal one in the complete version. The friction approach is more sensibly different since both the dependent and the explanatory variables are computed as the product of the variables that enter the odds specifications. Note also that we now use the real measure of transport costs (and its square) instead of its potentially noisy proxy constituted by distance.

There are advantages and drawbacks to the new approaches presented in this section. On the one hand, more data is needed. On the other hand, one might expect more robust results: Endogeneity concerns for regional sizes and wages for instance disappear in the friction specification and transport cost data should do a better job than distance at isolating the transport cost effects from the impact of networks. Second, new results are provided in terms of the impact of administrative borders on trade, and of networks on this border effect. Indeed, as recalled in the introduction, even elaborated methodologies have not succeeded in solving entirely the border effect puzzle. We investigate here whether network effects could be part of the explanation why borders seem to matter so much for trade patterns. The theoretical literature is actually fairly agnostic on the question of whether networks 
should impact trade (log) linearly with distance or not. If networks do not spill over borders and are bounded inside the regions where they are located, they could be responsible for the measured border effect. Border effects would consequently be a sort of statistical illusion, reflecting the bounded nature of networks following administrative borders, rather than a "real" cost incurred at the physical border. Specifications that consider the standard log-linear impact of distance, but also contiguity and border effects, allow to assess which trade impediments, the linear or the non-linear ones, are the most affected by networks. This is what we present in this section.

\subsection{The impact of networks in the complete odds and friction specifications}

\section{Significance and magnitude}

Results of estimations for the complete odds and the friction specifications are given in Tables 6 and 7 . respectively.

Table 6: Complete odds specification

\begin{tabular}{l|cccccc}
\hline \hline \multirow{3}{*}{ Model : } & \multicolumn{5}{|c}{ Dependent Variable: Bilateral flow relative to internal flow } \\
\cline { 2 - 7 } & $(1)$ & $(2)$ & $(3)$ & $(4)$ & $(5)$ & $(6)$ \\
\hline intercept & $-1.84^{a}$ & $-1.30^{a}$ & $-1.15^{a}$ & $-1.02^{a}$ & $-1.50^{a}$ & $-1.08^{a}$ \\
production & $(0.16)$ & $(0.16)$ & $(0.18)$ & $(0.18)$ & $(0.15)$ & $(0.17)$ \\
& $0.55^{a}$ & $0.41^{a}$ & $0.41^{a}$ & $0.37^{a}$ & $0.30^{a}$ & $0.24^{a}$ \\
wage & $(0.06)$ & $(0.06)$ & $(0.06)$ & $(0.06)$ & $(0.07)$ & $(0.07)$ \\
& $-1.99^{a}$ & $-1.01^{a}$ & $-2.60^{a}$ & $-1.89^{a}$ & $-3.35^{a}$ & $-3.09^{a}$ \\
transp. costs & $(0.43)$ & $(0.34)$ & $(0.44)$ & $(0.46)$ & $(0.46)$ & $(0.48)$ \\
& $-2.31^{a}$ & $-1.92^{a}$ & $-1.83^{a}$ & $-1.73^{a}$ & $-2.03^{a}$ & $-1.74^{a}$ \\
transp. costs sq. & $(0.11)$ & $(0.16)$ & $(0.14)$ & $(0.15)$ & $(0.12)$ & $(0.15)$ \\
& $2.5 \mathrm{e}-8^{a}$ & $1.3 \mathrm{e}-8$ & $1.1 \mathrm{e}-8$ & $0.8 \mathrm{e}-8$ & $1.2 \mathrm{e}-8$ & $0.5 \mathrm{e}-8$ \\
contiguity & $(0.8 \mathrm{e}-8)$ & $(0.9 \mathrm{e}-8)$ & $(0.8 \mathrm{e}-8)$ & $(0.8 \mathrm{e}-8)$ & $(0.8 \mathrm{e}-8)$ & $(0.9 \mathrm{e}-8)$ \\
& $0.88^{a}$ & $0.67^{a}$ & $0.61^{a}$ & $0.56^{a}$ & $0.87^{a}$ & $0.69^{a}$ \\
immigrants & $(0.08)$ & $(0.08)$ & $(0.09)$ & $(0.08)$ & $(0.07)$ & $(0.08)$ \\
& & $0.23^{a}$ & & $0.13^{a}$ & & 0.07 \\
emigrants & & $(0.04)$ & & $(0.05)$ & & $(0.05)$ \\
& & & $0.29^{a}$ & $0.22^{a}$ & & $0.14^{b}$ \\
plant links & & & $(0.05)$ & $(0.05)$ & & $(0.05)$ \\
& & & & & $0.48^{a}$ & $0.39^{a}$ \\
N & & & & & $(0.05)$ & $(0.05)$ \\
$\mathrm{R}^{2}$ & 7,491 & 7,491 & 7,491 & 7,491 & 7,491 & 7,491 \\
RMSE & 0.422 & 0.436 & 0.440 & 0.443 & 0.454 & 0.460 \\
\hline
\end{tabular}

Notes: ( $i$ ) All variables in logarithm and computed relatively to the value for the destination region itself (except the contiguity dummy): See equation (11). (ii) Robust standard errors in brackets. ${ }^{a},{ }^{b},{ }^{c}$ : Significance at the $1 \%, 5 \%, 10 \%$ levels, respectively.

According to theory, the relative production coefficient should be equal to 1 in the complete odds specification. This not the case here, as often in this kind of estimations. The impact of production is still largely positive, however. The estimate for relative wages is also low compared to theoretical expectations. This is another usual finding in the empirical literature estimating price elasticities using trade flows. Recent studies by Head and Ries (2001), Erkel-Rousse and Mirza (2002), Lai and Trefler (2002), or Hanson (1998) for instance, find higher estimates of price elasticity but have to rely on different estimation techniques and/or different types of data. Compared with existing studies estimating price elasticities in gravity-like equations, our levels for this parameter are actually fairly 
Table 7: Friction specification

\begin{tabular}{l|cccc}
\hline \hline \multirow{2}{*}{ Model : } & \multicolumn{4}{|c}{ Dependent Variable: Friction index } \\
\cline { 2 - 5 } & $(1)$ & $(2)$ & $(3)$ & $(4)$ \\
\hline intercept & $-1.93^{a}$ & $-1.00^{a}$ & $-1.41^{a}$ & $-0.98^{a}$ \\
& $(0.16)$ & $(0.21)$ & $(0.16)$ & $(0.19)$ \\
transp. cost & $-2.22^{a}$ & $-1.54^{a}$ & $-1.89^{a}$ & $-1.56^{a}$ \\
& $(0.11)$ & $(0.11)$ & $(0.10)$ & $(0.10)$ \\
transp. cost sq. & $2.3 \mathrm{e}-8^{b}$ & $0.2 \mathrm{e}-8$ & $0.5 \mathrm{e}-8$ & $-0.4 \mathrm{e}-8$ \\
& $(1.1 \mathrm{e}-8)$ & $(0.9 \mathrm{e}-8)$ & $(0.9 \mathrm{e}-8)$ & $(0.9 \mathrm{e}-8)$ \\
contiguity & $0.88^{a}$ & $0.53^{a}$ & $0.85^{a}$ & $0.66^{a}$ \\
& $(0.08)$ & $(0.09)$ & $(0.07)$ & $(0.08)$ \\
migrants & & $0.40^{a}$ & & $0.22^{a}$ \\
& & $(0.05)$ & & $(0.04)$ \\
plants & & & $0.65^{a}$ & $0.54^{a}$ \\
& & & $(0.07)$ & $(0.06)$ \\
\hline $\mathrm{N}$ & 3,413 & 3,413 & 3,413 & 3,413 \\
$\mathrm{R}^{2}$ & 0.511 & 0.544 & 0.570 & 0.579 \\
RMSE & 1.182 & 1.141 & 1.109 & 1.098 \\
\hline
\end{tabular}

Notes: (i) All variables are the logarithm of the product of bilateral values computed relatively to the values for regions themselves (except the contiguity dummy): See equation [13). (ii) Robust standard errors in brackets. ${ }^{a},{ }^{b},{ }^{c}$ : Significance at the $1 \%, 5 \%, 10 \%$ levels, respectively.

high. Moreover, we observe that the introduction of plant network effects notably increases those elasticities.

The estimation of the complete odds specification implies that transport costs impede trade flows, in the expected convex way. Estimates are very similar for the odds and the friction specifications. The quadratic term is only significant in the regressions without network controls. However, we choose to keep this variable because it improves the global fit of the model and leads to intermediate, and more realistic, levels of both border and transport costs effects. It has virtually no impact on the estimated network effects, which is our main interest here.

Both the magnitude and the significance of network effects are similar to those obtained in the specifications presented in Section 4. Considering internal flows and border effects do not alter the previous conclusions regarding the trade creating impact of networks. In terms of trade creation, the six figures of Table 5 for the complete odds specification would be $65.4 \%, 86.7 \%, 821.5 \%, 15.6 \%$, $34.5 \%$, and $494.7 \%$, which corresponds to the same magnitude as what is obtained with the basic odds specification. Migrant network effects are slightly smaller, however, and the impact of the plant networks is larger in the regression where all effects are introduced simultaneously. We thus confirm our previous finding that the magnitude of trade creation is much larger for plant networks than for migrant ones, which tends to support the information channel.

In order to improve our understanding of the magnitude of the impact of networks, Table 8 computes, for the average region, the (inverse) of the relevant term in equation (11):

$$
\left(\overline{\left(\frac{1+z_{i j}}{1+z_{i i}}\right)}\right)^{\widehat{\varrho}},
$$

where $\overline{\left(\frac{1+z_{i j}}{1+z_{i i}}\right)}$ is the average across regions of the impact of each network variable $\left(z_{i j}=\operatorname{mig}_{i j}, \operatorname{mig}_{j i}\right.$, plant $_{i j}$ ) and $\widehat{\varrho}$ the corresponding elasticity. The impact of both migrant (or plant) networks, or of all 
effects together, is also computed by summing these network effects, which are evaluated, however, with the estimates of the regressions that consider the effects of network variables simultaneously. We proceed similarly with the friction specification (equation 13 ).

Table 8: Network effects

\begin{tabular}{l|c|c|c|c|c|c|c|c|c}
\hline \hline & \multicolumn{4}{|c|}{ Separate } & \multicolumn{5}{c}{ Simultaneous } \\
\cline { 2 - 7 } & \multicolumn{3}{|c|}{ Migrants } & Plant links & \multicolumn{3}{c}{ Migrants } & Plant links & All \\
\cline { 2 - 6 } & Imm. & Em. & Both & & Imm. & Em. & Both & & \\
\hline Odds & 3.5 & 4.8 & 6.5 & 2.2 & 1.4 & 2.1 & 3.0 & 1.9 & 5.7 \\
Friction & - & - & 8.3 & 2.9 & - & - & 3.3 & 2.4 & 7.9 \\
\hline
\end{tabular}

The first figure in line "Odds" of Table 8 means that differences across regions in the number of immigrants relative to the number of people working in the region where they were born make, for the average region and when entering the regression separately, inter-regional trade flows 3.5 times lower than internal ones. As can be seen in column "Both", migrant network variables acting simultaneously but not controlling for plant networks would make inter-regional trade flows 6.5 lower than internal ones. The average difference between inter-regional and intra-regional plant networks lowers inter-regional trade by a factor of 2.2 when migrant networks are not controlled for. The hierarchy between the effects of migrant and plant networks therefore depends on the benchmark considered. When comparing inter-regional flows, plant networks are clearly dominant. On the contrary, when explaining the average surplus of trade taking place within administrative borders, the effects are reversed, suggesting that the spatial distribution of migrants is more governed by administrative borders than the distribution of plants.

When all network variables are considered simultaneously (right-hand side of Table 8, columns "Simultaneous"), the impact of migrant networks appears to be more than twice smaller, while the impact of plant networks decreases by less than 20\%. Migrant and plant network effects are of comparable magnitude. Finally, all network effects together make inter-regional flows 5.7 times lower than intra-regional ones now. The impact of networks in shaping trade flows is even larger according to the friction specification, which is our favourite estimation since it corrects for the potential endogeneity of production and wage variables. Business and social networks would make inter-regional flows nearly eight times lower than intra-regional ones in this case.

\section{Endogeneity}

There are two potential sources of endogeneity for the network variables ${ }^{20}$ One is linked to potentially omitted variables. An unobserved positive productivity shock in a region for instance may simultaneously raise trade flows and attract new plants or migrants, which induces a correlation between the error term and the network variables. The second source of endogeneity is linked to reverse causality. Large merchandize flows may mean that potential migrants will find the commodities they like in the destination region, which triggers migration. Similarly, firms might use the trade flow signal to take their location decision, anticipating for instance that they will find partners in the destination region, that production conditions are good, etc. In both cases, causality would go from trade flows to networks, biasing OLS estimates.

The way we address the potential endogeneity of network variables is twofold. First, the trade variable is a yearly flow whereas network variables correspond to total stocks of migrants and plants present in the region. This should reduce both the simultaneity and the reverse causality issues.

\footnotetext{
${ }^{20}$ Endogeneity of other variables in bilateral trade estimations has been rarely investigated, Harrigan (1996) being one exception. Recall that our friction specification is immune to such biases.
} 
Second, we perform some regressions where the 1993 migrant network variables are instrumented with their 1978 values. Since those correspond to stocks again, furthermore computed 15 years earlier than the date at which commodity flows are observed, we think they provide good instruments for migrant networks. Due to lack of space, instrumented regressions are presented in details in the working paper version (Combes et al., 2004), and we only comment on the main results here. The explanatory power of instruments is high. Depending on the regression, migrant network variables are or not endogenous, which shows that questioning possible endogeneity is indeed important. However, here, endogeneity appears to leave the estimations unaffected: if anything, endogeneity appears to introduce a downward bias only. All coefficients for migrant network variables are larger, even if slightly so in most cases, when instrumented. We are thus confident that our results are not caused by endogeneity issues.

\subsection{The decline in the estimates of trade impediments}

\section{Border effects without network controls}

The line "intercept" in Table 6 gives the coefficient needed to calculate the effect of administrative borders in France: -1.84 in column (1) means that inter-regional flows between two non contiguous regions are $\exp (1.84)=6.3$ times lower than intra-regional ones ceteris paribus, when network effects are not controlled for in the complete odds specification. Column (1) in Table 7 reports the estimates for the friction specification without networks effects and leads to a very similar value. The border effect is evaluated at $\exp (1.93)=6.9$. Interestingly, both values are only slightly larger than what Wolf (2000) finds for trade inside the United States in 1993, which is also the year we consider.

The contiguity variable allows to distinguish between two different kinds of border effects. The estimate reported in line "contiguity" in Table 6 means that, according to the estimation of the complete odds specification, inter-regional trade flows between two non-contiguous regions are $\exp (0.88)=2.4$ times lower than flows between two contiguous ones. Therefore, trade between two contiguous regions are $\exp (1.84-0.88)=2.6$ times lower than internal trade flows, which we call the "local border effect". In other words, the border effect can be decomposed as: $6.3=2.4 \times 2.6{ }^{21}$ Both drops in trade flows are of similar magnitude. Note also that the estimate of the contiguity effect is exactly the same in the friction specification ${ }^{22}$

\section{The impact of networks on the distance, border and contiguity effects}

Table 9 computes the changes in trade impediments when network variables are introduced. The first three lines correspond to estimates from the complete odds specification. For instance, the first figure indicates that when only immigrants networks are controlled for in the odds specification, the total border effect varies by $[\exp (1.30-1.84)-1]=-42.1 \%, 1.84$ and 1.30 being the estimates of the border effects taken from Table 6 columns (1) and (2), respectively. The other figures of the line are similarly computed with the other estimations. A similar procedure is then applied for the effect of contiguity ${ }^{23}$ The last line gives the variation for the average region of the transport cost effect given

\footnotetext{
${ }^{21}$ Note that $2.4 \times 2.6$ is not strictly equal to 6.3 because we present rounded figures.

${ }^{22}$ Changing the definitions of the internal transport cost, or including or not the contiguity dummy, modifies the magnitude of the border effect. This is mechanical since it directly corresponds to a translation in the intercept of the regression as is now well-established (see Wei, 1996, and Helliwell and Verdier, 2001, for instance). Our primary interest here is the way trade impediments are affected by networks. And indeed, we find this impact to be very similar across variants regarding distance, contiguity and border variables, the reason why we concentrate our presentation on one variant only.

${ }^{23}$ The variation of the contiguity effect is part of the variation of the border effect.
} 
by the (inverse of the) exponential of:

$$
\widehat{\sigma \delta} \ln \left[\overline{\left.\left(\frac{1+t_{i j}}{1+t_{i i}}\right)\right]}+\widehat{\sigma \theta}\left[\overline{\left(t_{i j}^{2}-t_{i i}^{2}\right)}\right] .\right.
$$

where $\overline{\left(\frac{1+t_{i j}}{1+t_{i i}}\right)}$ is the average across regions of the linear impact of the transport cost, and similarly for the quadratic impact.

Table 9: Network impact on distance, border and contiguity effects

\begin{tabular}{l|l|c|c|c|c|c}
\hline \hline \multirow{2}{*}{} & \multicolumn{5}{|c|}{ Separate } & Simultaneous \\
\cline { 3 - 5 } \multicolumn{2}{c|}{} & \multicolumn{3}{|c|}{ Migrants } & Plant links & All \\
\cline { 3 - 5 } \multicolumn{2}{c}{ Odds } & Imm. & Em. & Both & & \\
\hline \multirow{3}{*}{ Friction } & Border (\%) & -42.1 & -49.9 & -56.3 & -29.0 & -53.3 \\
& Contiguity (\%) & -18.7 & -23.0 & -26.9 & -0.8 & -17.3 \\
& Transport (\%) & -47.2 & -55.1 & -61.8 & -31.5 & -58.0 \\
\hline & Border (\%) & - & - & -60.4 & -40.3 & -61.4 \\
& Contiguity (\%) & - & - & -29.2 & -2.5 & -19.4 \\
& Transport (\%) & - & - & -70.4 & -41.5 & -67.8 \\
\hline
\end{tabular}

The last column in Table 9 shows that when introduced simultaneously, business and social networks have a strong impact on the border effect that decreases by $53.3 \%$ and $61.4 \%$ according to the complete odds and the friction specifications, respectively. Migrant networks make border effects decline slightly more than plant networks. Thus, the "network-part" of the usually estimated border effects would be more caused by missing migrant network variables than by plant network ones.

Second, the lines labelled "Contiguity" show that both components of the border effect (the local border effect and contiguity) are affected by networks. However, the local border effect variation is three times stronger than the contiguity one when all network variables are introduced simultaneously either in the complete odds or in the friction specifications. This can be interpreted as evidence that the effects of networks is stronger at very short distances than at intermediate ones. This is all the more true for plant networks for which the impact on the contiguity effect is virtually nil. The impacts of migrant networks are more balanced between the local border and the contiguity effects.

When network effects are not considered, the impact of transport costs for the average region, given by the mean of the transport cost effect given in equation (16), is equal to 88 . This means that the difference between inter-regional and intra-regional transport costs causes, for the average region, inter-regional trade flows to be 88 times lower than internal flows. Thus, transport costs largely impede trade, even when border effects are taken into account (with an impact much stronger than the one of borders actually). Noticeably, as reported in line "Odds" / "Transport" of Table 9, the decline of the transport cost impact is equal to $58.0 \%$ when all network effects are considered in the complete odds specification estimation. The magnitude of this decline is comparable to the border effect reduction. Emigrants also have a slightly stronger impact than immigrants. Last, the reduction implied by migrant networks only is twice as large as the one by plant networks ( $61.8 \%$ versus $31.5 \%)$. Again, this would mean that the spatial scope of migrant networks is wider, while plant networks would have more of a non-linear impact mainly acting on short distances. Similar conclusions can be drawn from the estimations of the friction specification, the implied variations being slightly larger.

\section{Conclusion}

We quantify in this paper the trade-creating effects of business and social networks emphasized recently by trade economists as an important theoretical and empirical determinant of international 
transactions. The results we obtain for the impact of migrations confirm the existing evidence in the literature. The average observed level of migrant stocks doubles trade flows compared to a situation without migration. While these migrant effects can be explained by both preference and information effects, we also provide new results regarding pure information business effects captured by the intensity of the links between plants belonging to the same business group. These links multiply trade flows by as much as four. These estimates are obtained under several and quite different methodologies, some of them instrumenting the possibly endogenous migrant network variables. The larger impact of plant networks, which cannot be attributed to preference effects, suggests that the information channel could be the main vector of the impact of networks.

We also show that network effects, when omitted, are captured to a wide extent by the set of variables that embody the impact of spatial proximity on trade flows (transport costs, borders and contiguity). Consequently, our results point to a potential overestimation in the literature of the effects of these variables. For instance, the impact of transport costs is reduced by as much as $68 \%$ when network controls are introduced. The unexplained remaining border effect is estimated to multiply internal flows by "only" 2.7, compared to inter-regional flows between two non-contiguous regions. This ratio is equal to 6.9 when network variables are omitted. Although those multiplicative factors could still seem to be large numbers for a country as integrated as France, they are comparable to what Wolf (2000) finds for the effect of states' borders inside the United States.

Improvements in the quantification of the role of business and social networks on trade can take several forms. First, progress can be made in terms of the variety of network proxies and instruments used. Next, attempts to improve the separate identification of information and preference effects should be continued. Last, and more generally, the theoretical underpinnings of the network block of our trade model could also be improved in order to provide more structure to this part of the estimation. 


\section{References}

Abowd, J., Kramarz, F., Margolis, D., 1999. High wage workers and high wage firms. Econometrica 67, 251-333.

ACFCI, 2002, Rapport annuel d'activités des CCI.http://www.acfci.cci.fr/presentationACFCI/ index.htm\#rac02

Anderson, S., De Palma, A., Thisse, J.-F., 1992, Discrete Choice Theory of Product Differentiation. MIT Press, Cambridge.

Anderson, J., van Wincoop, E., 2003. Gravity with gravitas: a solution to the border puzzle. American Economic Review 93, 170-192.

Belderbos, R., Sleuwaegen, L., 1998. Tariff jumping DFI and export substitution: Japanese electronics firms in Europe. International Journal of Industrial Organization 16(5), 601-638.

Chen, N., 2004. Intra-national versus international trade in the European Union: why do national borders matter? Journal of International Economics 63(1), 93-118.

Combes, P-P., Lafourcade, M., 2004. Transport costs: measures, determinants and regional policy implications for France. Revised version of CEPR Discussion Paper 3958 (http://www.enpc.fr/ ceras/lafourcade/artdes.pdf)

Combes, P-P., Lafourcade, M., Mayer, T., 2004. The trade creating effects of business and social networks: evidence from France. CERAS Working Paper 04-04.

Disdier, A-C., Head, K., 2004. Exaggerated reports of the death of distance: lessons from a metaanalysis. mimeo U. of Paris 1 (http://team.univ-paris1.fr/teamperso/disdier/meta.pdf).

Dixit, A., Stiglitz, J., 1977. Monopolistic competition and optimum product diversity. American Economic Review 67(3), 297-308.

Eaton, J., Kortum, S., 2002. Technology, geography and trade. Econometrica 70(5), 1741-1780.

Erkel-Rousse, H., Mirza, D., 2002. Import price-elasticities: reconsidering the evidence. Canadian Journal of Economics 35(2), 282-306.

Ethier, W., 1982. National and international returns to scale in the modern theory of international trade. American Economic Review 72, 389-405.

Feenstra, R., 2003, Advanced International Trade: Theory and Evidence. Princeton University Press, Princeton.

Girma, S., Yu, Z., 2002. The link between immigration and trade: evidence from the United Kingdom. Weltwirtschaftliches Archiv 138(1), 115-130.

Gould, D., 1994. Immigrant links to home country: empirical implications for US bilateral trade flows. Review of Economics and Statistics 76, 302-316.

Hanson, G., 1998. Market potential, increasing returns, and geographic concentration. NBER Working Paper, 6429. Revised 2004 version available at: http://www2-irps.ucsd.edu/faculty/ gohanson/Uscnty.pdf

Harrigan, J., 1996. Openness to trade in manufactures in the OECD. Journal of International Economics 40(1-2), 23-39.

Head, K., Mayer, T., 2000. Non-Europe : the magnitude and causes of market fragmentation in Europe. Weltwirtschaftliches Archiv 136(2), 285-314.

Head, K., Ries, J., 2001. Increasing returns versus national product differentiation as an explanation for the pattern of US-Canada trade. American Economic Review 91(4), 858-876.

Head, K., Ries, J., Spencer, B., 2004. Vertical networks and U.S. auto parts exports: is Japan different? Journal of Economics Management and Strategy 13(1), 37-67.

Helliwell, J., 1996. Do national borders matter for Quebec's trade? Canadian Journal of Economics $29(3), 507-522$.

Helliwell, J., 1997. National borders, trade and migration. Pacific Economic Review 3(3), 165-185.

Helliwell, J., Verdier, G., 2001. Measuring internal trade distances: a new method applied to estimate provincial border effects in Canada. Canadian Journal of Economics 34(4), 1024-1041. 
Hillberry, R., Hummels, D., 2003. Intra-national home bias: some explanations. Review of Economics and Statistics 85(4), 1089-1092.

Hummels, D., 1999. Towards a geography of trade costs. Krannert School of Management mimeo (http://www.mgmt.purdue.edu/faculty/hummelsd/research/toward/Toward3.pdf).

INSEE, 2001. Le zonage en aires urbaines en 1999: 4 millions d'habitants en plus dans les aires urbaines. INSEE Première 765.

Krugman, P., 1980. Scale economies, product differentiation, and the pattern of trade. American Economic Review 70, 950-959.

Lai, N., Trefler, D., 2002. The gains from trade with monopolistic competition: specification, estimation, and mis-specification. NBER Working Paper, 9169.

Lawrence, R., 1993. Japan's different trade regime: an analysis with particular reference to keiretsu. Journal of Economic Perspectives 7(3), 3-19.

Limão, N., Venables, A., 2001. Infrastructure, geographical disadvantage, transport costs and trade. World Bank Economic Review 15(3), 451-479.

McCallum, J., 1995. National borders matter: Canada-US regional trade patterns. American Economic Review 85, 615-23.

Ministry of the Interior (DGCL), 2003, Budgets primitifs des départements 2003.

http://www.dgcl.interieur.gouv.fr/Publications/budgets_primitifs_departements_2003/accueil_budget_departements_ 2003.htm

Nitsch, V., 2000. National borders and international trade: evidence from the European Union. Canadian Journal of Economics 22(4), 1091-1105.

Obstfeld, M., Rogoff, K., 2000. The six major puzzles in international macroeconomics: is there a common cause? in Bernanke, B., Rogoff, K. (Eds.) NBER Macroeconomics Annual 2000.

Parsley, D., Wei, S-J., 2001. Explaining the border effect: the role of exchange rate variability, shipping costs and geography. Journal of International Economics 55(1), 87-105.

Rauch, J., 2001. Business and social networks in international trade. Journal of Economic Literature 39, 1177-1203.

Rauch, J., Trindade, V., 2002. Ethnic Chinese networks in international trade. Review of Economics and Statistics 84(1), 116-130.

Redding, S., Venables, A., 2004. Economic geography and international inequality. Journal of International Economics 62(1), 53-82.

Rose, A., 2000. One money, One market: the effect of common currencies on trade. Economic Policy 15(30), 7-46.

Taglioni, D., 2002. Exchange rate volatility as a barrier to trade: new methodologies and recent evidence. Economie Internationale 89/90, 227-259.

Wagner, D., Head, K., Ries, J., 2002. Immigration and the trade of provinces. Scottish Journal of Political Economy 49(5), 507-525.

Wei, S-J., 1996. Intra-national versus international trade: how stubborn are nations in global integration? NBER Working Paper, 5531.

Wolf, H., 2000. Intranational home bias in trade. Review of Economics and Statistics 82(4), $555-563$. 